\title{
Experimental Studies on the Flameproofing Efficiency of Some Inorganic Substances upon the Inflammation of Wood and Fibrous Materials

\author{
${ }^{1}$ Olga A. Ivchenko, ${ }^{2}$ Kirill E. Pankin, ${ }^{3}$ Elena V. Kusmartseva, ${ }^{4}$ Sergey A. Anisimov, ${ }^{5}$ Aleksandr V. \\ Tutin \\ 1,2,3,4,5 Department of Techno Sphere Safety and Transport-Technology Machines, Federal State Budget \\ Education Institution of Higher Education "Saratov State Agrarian University named after N.I. Vavilov", \\ Saratov, Russian Federation \\ olgalexan607@mail.ru \\ texmexium@mail.ru \\ aleksandartiutin@yandex.ru
}

Received: 21st August 2020, Accepted: 14th September 2020, Published: 31st October 2020

\begin{abstract}
Preventing forest and steppe fires, as well as reducing damage from them, is unthinkable without the development and application of effective fire protective measures. Studies show, that there is a limited number of technological methods used to fight forest fires in the arsenal of forest fire services, for example, mineralized strips are most often used as a fire barrier or controlled counterfire of territory is organized. These measures either do not have sufficient efficiency, or they have increased danger themselves. There is another possibility of creating a fire barrier by reducing the fire hazard of forest debris by treating them with fire retardants similar to that used for the production of building materials. The paper presents the results for a study of the use of potential fire-retardant materials to reduce the ability to ignite wood (slats 10x10) and plant fibrous materials (flax hemp twine). Based on the analysis of literature data, substances based on aluminium, boron, magnesium and sodium chloride were selected as fire retardant materials. A method for investigating the fire-retardant action of the substances under study has been developed, which makes it possible to record the time of ignition of the samples from a constant power ignition source. A criterion for the fire-retardant action of the substances under study ( $>20 \mathrm{~min}$ ) has been developed, which is determined from the limiting combustion time of fragments of forest debris that can be carried by convective flows from fire and wind. Multiple studies of samples treated with flame retardants have been carried out. It was shown that substances based on aluminium and boron have the greatest fire-retardant effect, while magnesium and chlorine did not show a serious fireretardant effect. An additive fire retardant effect in case of repeated processing was revealed; it is similar to the use of more concentrated compositions. It is noted that more ample amount of fire-retardant materials is required for the protection of fibrous materials, than for wood samples, which, apparently, is the effect of the developed surface of the sample.
\end{abstract}

Keywords

Burning, Wood and Fibrous Materials, Flame Retardants.

\section{Introduction}

Prevention of forest and steppe fires is an important component of forestry and agriculture. It is assumed to conduct fire-prevention propaganda, to limit economic activity in forests, etc. in the capacity of preventive measures [1-3]. If fire cannot be prevented, damage from it should be minimized as much as possible. To do this, they carry out the construction of protective fire breaks, fire clearances, lines and barriers dividing out a forest area into separate sections, or quarters. Preventive measures taken in the forest area also contribute to the conduct of fire fighting operations by hindering fire movement. Nevertheless, these activities lose their effectiveness from year to year, and this happens not only in Russia, but also not in the territories of other countries rich in forest resources (USA, Canada, etc.), due to the following reasons: (1) inadequacy of firefighting measures; (2) their inefficiency. The first reason is in the field of activity of the regional forestry administrations [1]; the second reason requires a separate study, identification and elimination of weaknesses of protective measures.

A forest fire spread is carried out by moving its edge from one area to another. The forest area is rich in combustible materials: woody and herbaceous plants, dead wood, brushwood, forest litter, etc. generally referred to as forest debris. It is possible to stop the movement of a forest fire if it would be possible to remove forest debris from a certain area. This technique is applied by creating a fire barrier: a mineralized strip, the requirements for the arrangement of which are set out in the regulatory documents [4]. It is shown in [5] that the mineralized strip is not an effective fire barrier due to the absence of a $100 \%$ guarantee against the transfer of flame from one its side to another. In this regard, when arranging fire traps, another method of soil 
mineralization is used, or controlled counter fire of the territory; a counter fire is also used when extinguishing fires $[2,3]$. In this case, a controlled counter fire of forest debris is carried out in front of the edge of the fire and the fire hazard of the territory is reduced. It should be noted that a controlled counter fire is a dangerous procedure due to the high probability of loss of control over the process, especially during a fire hazardous period.

Are there other safer and less costly ways to convert forest fuels into non-combustible, or at least combustible ones? There is such a method: this is the treatment of forest debris and dead wood with combustion retarders, or fire retardants and substances that have found wide application in fire protection of building materials of plant or synthetic origin [6]. A serious limitation of the use of fire retardants in natural landscapes is the lack of any experimental data on the effectiveness of their fire retardant action, as well as their environmental impact on wildlife. This work is devoted to the issue of experimental study on the fire-retardant effect of substances based on aluminium, magnesium, boron and sodium chloride applied on forest debris.

To address the issue of the use of fire retardants to reduce the ability to ignite and slow down the combustion of forest debris and wildlife, it is necessary to formulate, develop and substantiate the criteria according to which the requirements for fire protection of forest debris will be put forward. To solve this issue, the starting point can be the fire resistance limit, or a parameter (measured in minutes) that characterizes the resistance of a structure to an open flame or high temperature. In our case, it is necessary to modify this parameter and determine the effective resistance of a combustible material to ignition, which can also be measured in units of time (seconds, minutes, etc.), and also find the factors that affect the indicated efficiency. An open question remains how to determine what limit of fire-retardant action is necessary for plant materials treated with fire retardants, which is necessary in the conditions of the development and spread of forest and steppe fires. In [5], the results of experimental studies on the possibility of transport by convective currents and wind, as well as the duration of burning of fragments, forest debris of various shapes and sizes are presented; it is also shown that the largest of the air-transported burning fragments of forest debris are capable of burning independently for 15-20 minutes. Thus, within the specified time, they are able to act as independent sources of ignition, and if a fire-retardant effect for forest debris is provided for more than 20 minutes, then it will be possible to prevent the occurrence and spread of the edge of a fire over the natural landscape.

Another important issue concerning the use of fire retardants in wildlife is their possible phytotoxic and environmental impact, which has not been systematically studied in living systems due to the lack of need. This is not so important in the manufacture of building materials of plant origin, because work is carried out with dead wood or wood fibres, and increasing the fire resistance, preserving effect, protection from the destructive effects of insects and fungi in the manufacture of building structures is only welcome [7, 8]. Most of the fire retardants used for the production of building materials are inorganic compounds based on ammonia salts, sulphuric or phosphoric acids, silicon, magnesium, boron, iron, zinc, copper, titanium-containing substances, etc. [9-22].

\section{Materials and Methods}

To study the fire protection effect of fire retardants on plant materials, four compounds were selected: aluminium hydroxide $\left(\mathrm{Al}(\mathrm{OH})_{3}\right)$, obtained by hydrolysis of its salt (aluminium sulphate) in water and magnesium hydroxide $\left(\mathrm{Mg}(\mathrm{OH})_{2}\right)$ also obtained by hydrolysis, tetraborate sodium, and sodium chloride. Analysis of the literature [23] showed that compounds of magnesium, aluminium and boron have fire retardant properties. In addition, magnesium and aluminium compounds are components of the natural environment (the mineral soil skeleton and components of natural water), and magnesium is a part of chlorophyll, which ensures the process of photosynthesis. Sodium chloride was chosen as a comparison and determination of the possible flame retardant function of chloride ions, which is also present in magnesium chloride, because some chlorine compounds act as combustion inhibitors [24,25]. Thus, the selected range of fire retardants does not differ from the component composition of the environment and should not have pronounced phytotoxic properties.

When treating territory of a natural landscape with fire retardants, it is most convenient to use a spraying method using water as a solvent. This, on the one hand, imposes restrictions on the fire retardants used, and on the other hand, provides the supply of fire retardants only on the surface of woody and non-woody vegetation that are in direct contact with the ignition source: bark of tree-like plants, leaf surface of herbaceous plants, and forest litter. In a fire hazardous period, most of the above is a collection of dead plant residues, for which phytotoxicity is no longer relevant.

To determine experimentally the fire-retardant action of the substances under study, it is necessary to simulate the effect of an ignition source on samples which composition and structure are close to forest debris. We considered wooden slats 10x10 mm made of coniferous wood (Scots pine) as samples for imitating forest debris, which is most common in central Russia and Siberia and, at the same time, is the most fire hazardous [2, 3]. Twine (cord) made from a mixture of flax and hemp fibrous materials, was used as a model for studying the ignition of non-woody vegetation (herbage). The experimental study consisted in determining the time spent on heating the sample of a material of plant origin (slats and twine) before the appearance of stable flaming 
combustion on the experimental sample. As defined above, the experiment time was limited to 20 minutes. A tourist gas stove was used as a heating source, the ignition source in which was the flame of a propane-butane mixture supplied to the stove from a cylinder. To ensure the constancy of the experimental conditions, the flow rate of the combustible mixture in the ignition source was selected in such a way as to ensure stable combustion at a minimum flow rate. Preliminary experiments have shown that the minimum consumption of the combustible mixture in the ignition source does not depend on the amount of the gas mixture in the cylinder or on the pressure in it. The sample (slats, twine) was placed on a stand above the gas burner flame horizontally so that the diffusion combustion zone of the gas burner flame did not come into contact with the sample surface and the heating was carried out by a convective flow of heated combustion products of the propane-butane mixture and heat radiation emanating from the combustion zone. It was experimentally revealed that the optimal distance between the sample and the burner is $80 \mathrm{~mm}$, while the ignition time of the test sample is more than 1 minute, which is well recorded by a stopwatch.

Aluminium sulphate, magnesium chloride, sodium tetraborate and sodium chloride of technical purity were used to create fire retardants. Samples of these substances were weighed using an AnD Gh-200 laboratory (analytical) balance (error e $\approx 1 \mathrm{mg}$ ) and then dissolved in tap water to obtain solutions with the required concentration (Table 1). The treatment of experimental samples with a solution of fire retardants was carried out by applying them to the surface with a brush at $75 \%$ of the length of the sample (slats) in order to compare the effect of the ignition source on the treated and untreated areas. Fibrous materials were treated with a flame retardant along their entire length, and samples of untreated twine were used as a comparison. After processing, the samples were dried for a day, and some of the samples were subjected to secondary processing followed by drying to reveal the effect of the multiple processing on the fire retardant effect.

\section{Results}

Table 1 shows the results for a study of the fire protection effect of fire retardants on samples of wood and fibrous materials. Time $t_{1}$ and $t_{2}$ is the average firing duration (in a series of experiments) of samples simulating plant materials treated with solutions of fire retardants once and twice. The parameter $n$ characterizes the number of parallel experiments.

Table 1: The Results of the Study of Wood and Fibrous Plant Materials Fire Resistance When treated with Various Types of Fire Retardants.

\begin{tabular}{|c|c|c|c|c|c|c|c|}
\hline \multirow[t]{2}{*}{$\mathrm{C}, \mathrm{g} / \mathrm{l}$} & & \multicolumn{3}{|c|}{ Wood } & \multicolumn{3}{|c|}{ Fibrous twine } \\
\hline & $\mathrm{n}$ & $\mathrm{t}_{1}$, min. & $\mathrm{n}$ & $\mathrm{t}_{2}, \mathrm{~min}$. & $\mathrm{n}$ & $\mathrm{t}_{1}, \mathrm{~min}$. & $\mathrm{t}_{2}, \mathrm{~min}$. \\
\hline \multicolumn{8}{|c|}{ Aluminum sulfate } \\
\hline 0 & 18 & 3,67 & - & - & 6 & 2,69 & - \\
\hline 1,7 & 6 & 16,60 & 4 & 14,43 & 8 & 6,24 & 11,2 \\
\hline 3,5 & 4 & 18,76 & 6 & $>20$ & 6 & 5,58 & 9,12 \\
\hline 8,4 & 4 & $>20$ & 6 & $>20$ & 6 & 11,71 & $>20$ \\
\hline \multicolumn{8}{|c|}{ Magnesium chloride } \\
\hline 0 & 18 & 3,67 & - & - & 6 & 2,69 & - \\
\hline 6,5 & 7 & 2,98 & 7 & 3,14 & 6 & 3,15 & 5,71 \\
\hline 52,5 & 5 & 9,12 & 5 & 8,52 & 6 & 3,73 & 6,82 \\
\hline 110,0 & 4 & 8,15 & 6 & $>20$ & 6 & 9,22 & $>20$ \\
\hline 176,0 & 4 & $>20$ & 3 & $>20$ & 6 & $>20$ & $>20$ \\
\hline \multicolumn{8}{|c|}{ Sodium chloride } \\
\hline 0 & 18 & 3,67 & - & - & 6 & 2,69 & - \\
\hline 26,0 & 6 & 4,68 & 5 & 9,66 & 6 & 3,17 & 10,3 \\
\hline 52,5 & 4 & 7,79 & 3 & 12,51 & 6 & 3,02 & 9,17 \\
\hline \multicolumn{8}{|c|}{ Sodium pyroborate } \\
\hline 0 & 18 & 3,67 & - & - & 6 & 2,69 & - \\
\hline 13 & 4 & $>20$ & 2 & $>20$ & 6 & 15,70 & $>20$ \\
\hline
\end{tabular}

\section{Results and Discussion}

Based on the data obtained experimentally, it can be concluded that among the samples under study, aluminium and boron compounds have the greatest fire protection effect. Magnesium chloride exhibits flame retardant properties under experimental conditions only at very high concentrations of 52-176 g / 1 . It was not possible to obtain a high concentration of magnesium chloride under laboratory conditions. Sodium chloride proved to be unable to prevent the combustion of samples of either wood or fibrous materials up to a solution concentration of $52.5 \mathrm{~g} / 1$ and applying a double treatment. In most cases, an increase in the concentration of fire retardant solutions leads to an increase in the time of resistance of samples to flammability, as well as the frequency of 
treatment of samples with a solution. Both of these parameters turned out to be additively related to each other, which is explained by the additive effect for the masses of fire retardants falling the surface of the protected material. Analysis of the results of processing fibrous materials in comparison with wood materials revealed, in most cases, a lower fire-retardant effect of the investigated fire retardants on fibrous materials compared to wood. The only exception is the treatment of samples with a solution of sodium tetraborate with a concentration of $13 \mathrm{~g} / 1$, which was able to protect samples of both wood and fibrous materials for 20 minutes. Observation of the ignition source effect on the samples treated and untreated with fire retardants showed the obligatory carbonization stage available for samples, but carbonization and ignition began somewhat later on the samples treated with a solution of a fire retardant,. Starting from a certain concentration threshold of the fire retardant in the solution, charring of the samples of wood and fibrous materials was observed in 20 minutes without their subsequent ignition.

\section{Conclusion}

The research gave the following results:

1) Certain types of fire retardants for processing samples of wood and fibrous combustible materials were selected.

2) A technique has been developed for the experimental study of the fire protection action of fire retardants on wood and fibrous combustible materials, also studies of the fire protection action of inorganic substances based on aluminium, boron, magnesium and sodium have been carried out.

3) It has been experimentally shown that compounds based on aluminium and boron have the best fire-retardant properties, while magnesium and sodium chlorides are unable to provide the required degree of fire protective action for either wood or fibrous materials.

4) An additive relationship between the concentration of the fire retardant solution used for processing the test samples and the frequency of the procedure for processing the test samples with fire retardants was revealed.

\section{References}

1. Forest Code of the Russian Federation dated 04.12.2006 N 200-FZ (as amended on 03.08.2018) [Electronic resource] (with amendments and additions that came into force on 01.09.2018)

2. Field guide of a forest firefighter [Electronic resource].- Access mode: http://www.forestforum.ru/info/fireman.pdf

3. A guide of a voluntary forest firefighter [Electronic resource]. - Access mode: https://aviales.ru/files/documents/2013/02/spravochnik.pdf

4. OST 56-103-98 Protection of forests from fires. Fire breaks and mineralized bands. Condition quality assessment criteria. Industry standard. Date of introduction 01.07.1998.

5. Questions of forest pyrology: a collection of articles [Text] .- Krasnoyarsk: 1970.- 558 p.

6. Kodolov V.I. Fire retardants for polymeric materials [Text] / V.I. Kodolov. - Moscow: Chemistry, 1980. - 274 p.

7. Rasev A.I., Kosarin A.A., Krasukhina L.P. Technology and equipment for wood protection [Text] / A.I. Rasev, A.A. Kosarin, L.P. Krasukhina - MSFU (Moscow State Forestry University), 2010 .- 171 p.

8. Handbook of Wood Chemistry and Wood Composites. Second Edition [Text], CRC Press, 2012, 703p.

9. Intumescent fire protective coating: Toward a better understanding of their mechanism of action [Text] / M. Jimenez, S. Duquesne, S. Bourbigot // Thermochimica Acta.- 2006.- Vol. 449.- pp. 16-26.

10. Testing the retardancy effect of various inorganic chemicals on smoldering combustion of Pinus halepensis needles [Text] / S. Liodakis, D. Vorisis, I.P. Agiovlasitis // Thermochimica Acta.- 2006-Vol. 444.- pp. 157165.

11. Ash properties of Pinus halepensis needles treated with diammonium phosphate [Text] / S. Liodakis, G. Katsigiannis, T. Lymperopoulou // Thermochimica Acta.- 2007.-Vol. 453.- pp. 136-146.

12. Testing the fire retardancy of Greek minerals hydromagnesite and huntite on WUI forest species Phillyrea latifolia L. [Text] / S. Liodakis, I. Antonopoulos, I.P. Agiovlasitis, T. Kakardakis // Thermochimica Acta.2008.- Vol.469 .- pp. 43-51.

13. Fire retardancy impact of sodium bicarbonate on ligno-cellulosic materials [Text] / D. Bakirtzis, M.A. Delichatsios, S. Liodakis, W. Ahmed// Thermochimica Acta.- 2009.- Vol. 486.- pp. 11-19.

14. Synergistic effect of iron and intumescent flame retardant on shape-stabilized phase change material [Text] / P. Zhang, Y. Hu, L. Song, H. Lu, J. Wang, Q. Liu // Thermochimica Acta.- 2009.- Vol. 487.- pp. 74-79.

15. Flame retardancy mechanisms of bisphenol A bis(diphenyl phosphate) in combination with zinc borate in bisphenol A polycarbonate/acrylonitrile-butadiene-styrene blends [Text] / K.H. Pawlowski, B. Schartel, M.A. Fichera, C. Joger // Thermochimica Acta.- 2010.- Vol. 498.- pp. 92-99.

16. A novel durable flame-retardant cotton fabric using sodium hypophosphite, nano $\mathrm{TiO}_{2}$ and maleic acid [Text] / F. Lessan, M. Montazer, M.B. Moghadam // Thermochimica Acta.- 2011.- Vol. 520.- pp. $48-54$. 
17. Synthesis and carbonization chemistry of a phosphorous-nitrogen based intumescent flame retardant [Text] / H. Ma, Z. Fang // Thermochimica Acta.- 2012.- Vol. 543.- pp. 130- 136.

18. The effect of some wood preservatives on the thermal degradation of Scots pine [Text] / E.D. Tomaka, E. Baysal, H. Peker // Thermochimica Acta.- 2012.- Vol. 547.- pp. 76- 82.

19. ATR investigation of the mass residue from the pyrolysis of fire retarded lignocellulosic materials [Text] / D. Bakirtzis, V. Tsapara, S. Liodakis, M.A. Delichatsios // Thermochimica Acta.- 2012.- Vol. 550.- pp. 48- 52.

20. Thermal characterization of new fire-insulating materials from industrial inorganic $\mathrm{TiO}_{2}$ wastes [Text] / S.M. Perez-Moreno, M.J. Gazquez, A.G. Barneto, J.P. Bolivar // Thermochimica Acta.-2013.-Vol.552.-pp.114122.

21. Thermal analysis of Pinus silvestris L. wood samples treated with anew gel-mineral mixture of short- and long-term fire retardants [Text] / S. Liodakis, V. Tsapara, I.P. Agiovlasitis, D. Vorisis // Thermochimica Acta.2013.- Vol. 568.- pp. $156-160$.

22. Aluminium diethylphosphinate versus ammonium polyphosphate: Acomprehensive comparison of the chemical interactions duringpyrolysis in flame-retarded polyolefine/poly(phenylene oxide) [Text] / A. Sut, S. Greiser, C. Jager, B. Schartel // Thermochimica Acta.- 2016.- Vol. 640.- pp. 74-84.

23. URL: http://isolpro.ru/izolyatsiya/materialy/ognezashhita/antipireny/ (Access date: 10 November, 2018);

24. Berlin A.A. Combustion of polymeric materials and polymeric materials of low combustibility [Text] / A.A. Berlin // Soros Educational Journal. - 1996. - No. 9.- P.57-63.

25. Petrova A.N., Kapranov A.V., Anosova E.B. Study of toxic and fire hazard of synthetic building materials / A.N. Petrova, A.V. Kapranov, E.B. Anosova // Advances in chemistry and chemical technology.- 2016.Vol.30.- №8.- P.34-37. 